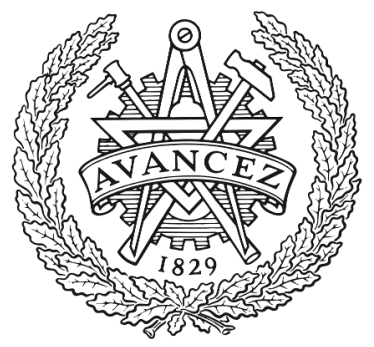

CHALMERS

UNIVERSITY OF TECHNOLOGY

\title{
Occupant injuries in light passenger vehicles - A NASS study to enable priorities for development of injury prediction capabilities of human body
}

Downloaded from: https://research.chalmers.se, 2023-04-26 09:21 UTC

Citation for the original published paper (version of record):

Pipkorn, B., Iraeus, J., Linquist, M. et al (2020). Occupant injuries in light passenger vehicles - A

NASS study to enable priorities for

development of injury prediction capabilities of human body models. Accident Analysis and Prevention, 138. http://dx.doi.org/10.1016/j.aap.2020.105443

N.B. When citing this work, cite the original published paper. 


\title{
Occupant injuries in light passenger vehicles-A NASS study to enable priorities for development of injury prediction capabilities of human body models
}

\author{
Bengt Pipkorn ${ }^{\mathrm{a}, *}$, Johan Iraeus ${ }^{\mathrm{b}}$, Mats Lindkvist ${ }^{\mathrm{c}}$, Pradeep Puthan ${ }^{\mathrm{d}}$, Olle Bunketorp ${ }^{\mathrm{e}}$ \\ a Autoliv Research, SE-447 83, Vårgårda, Sweden \\ ${ }^{\mathrm{b}}$ Chalmers University of Technology, Sweden \\ ${ }^{\mathrm{c}}$ Umeå University, Sweden \\ ${ }^{\mathrm{d}}$ Autoliv, India \\ ${ }^{\text {e }}$ Sahlgrenska Academy, Department of Orthopaedics, University of Gothenburg, Sweden
}

\section{A R T I C L E I N F O}

\section{Keywords:}

NASS

Body region

AIS2+

Injuries

Frontal

Oblique

Side

Impact

\begin{abstract}
A B S T R A C T
To prioritize how the development of mathematical human body models for injury prediction in crash safety analysis should be made, the most frequent injuries in the NASS CDS data from 2000 to 2015 were analyzed. The crashes were divided into seven types, from front to side. Non-minor injuries (AIS2+) were analyzed in two steps. In the first step, a grouping was made according to the AIS definition of body regions: head, face, neck, thorax, abdomen and pelvic contents, spine, upper extremities (including shoulder girdle) and lower extremities (including pelvis). In a second step, the body regions were divided in organs, parts of the spine, and parts of the extremities. The three most often injured anatomical structures of each body region were estimated for drivers and front seat passengers in each type of crash.

For drivers, an injury risk greater than $2.4 \%$ was found for the lower extremities (pelvis) and the head (concussion) in side oblique near side impacts, for the head in frontal oblique near side impacts (concussion) and for the lower extremities (ankle joint) in frontal impacts. For passengers, an injury risk greater than $2.4 \%$ was found for the thorax (lungs) in side near side impacts, for the head (concussion) in front oblique near side impacts, and for the thorax (sternum) and the upper extremities (wrist, hand) in frontal impacts.

Future development of human body models should focus on injuries to the head, thorax and the lower extremities. More specifically, it should focus on concussion in all impact directions and on rib and pelvic fractures in side near side impacts and in side oblique near side impacts.
\end{abstract}

\section{Introduction}

Traditionally, development and evaluation of passive vehicle safety, such as restraint systems, have been carried out by using anthropometric test dummies (ATDs) in laboratory crash testing and FE-simulations. These ATDs are developed for specific crash directions, such as the HIII and THOR for frontal collisions (Foster et al., 1977; Parent et al., 2013) and the EuroSID and WorldSID for side collisions (Neilson et al., 1985; Lowne and Neilson, 1987; Page, 2001). Furthermore, these ATDs have been developed to evaluate injury risk using regional injury criteria, for example chest deflection to evaluate the risk of thoracic injuries. In this case, different risk curves are available, representing different AIS levels. However, the injury is not related to any specific anatomical structure. Finally, these ATDs have limited ability to reproduce human kinematics in other crash directions than pure frontal and side impacts, since this is not included in the dummy calibration procedure.

In recent years, mathematical Human Body Models (HBMs) have been proposed as a complement to mechanical ATDs for development and evaluation of passive vehicle safety. The two major HBMs of today, representing average-sized males, are the Total Human Model for Safety (THUMS) AM50 (Toyota Central R\&D Labs, 2018) and the Global Human Body Model Consortium (GHBMC) M50-O model (Elemance, 2018). HBMs have several advantages in comparison to the mechanical ATDs. For example, as HBMs have detailed representation of the human anatomy, the injury risk can be evaluated on tissue level in any anatomical structure included in the model. The models can enable evaluation of physical variables mechanically related to injury, e.g. energy

\footnotetext{
* Corresponding author.

E-mail address: bengt.pipkorn@autoliv.com (B. Pipkorn).
} 
and strain (Rouhana et al., 2003). Another advantage is that HBMs with proper validation have a potential to become more biofidelic for all loading modes, including oblique impacts, due to the fact that the representation of the anatomy is more realistic than in ATDs.

Another important aspect to take into consideration is the future introduction of $\mathrm{AD}$ (Automatic Drive) vehicles. The usage of these vehicles may change body posture, seating position and orientation of the occupants compared with today's vehicles. It is therefore important that an analysis of a database containing today's vehicles is performed with the perspective of future $\mathrm{AD}$ vehicles. This perspective should also include the fact that there will be a shift in crash configurations that imposes the largest injury frequency as a result of $\mathrm{AD}$ crash avoiding technologies. It was shown that future vehicles with crash avoidance technology can eliminate most frontal and roll-over crashes while most side and rear-end impact will remain (Klinich et al., 2016). It was also shown that four crash types will represent $85 \%$ of all AIS2 + injury crashes in the future (Östling et al., 2019). These are: A; Head-On, B; Turn Across Path, Initial Opposite Direction, C; Turn into Opposite Direction and D; Straight Crossing Paths.

The objective of this study is therefore to provide a foundation for prioritizing further HBM development by describing the injury patterns for moderate to severe injuries of light passenger vehicle front seat occupants in frontal, oblique, and side impacts.

\section{Method}

The study is based on NASS/CDS data cases from years 2000 through 2015. The inclusion criteria were: car model year 2000 or later; restrained front seated occupant at least 15 years of age. The exclusion criteria were: rollover; multiple impacts; and vehicles older than or equal to 10 years at the time of impact. Weighted data were used for the analysis and cases with NASS weighting factor (RATWGT) higher than 5 000 were trimmed to 5000 (Kononen et al., 2011).

The crash types were selected as result of a perspective of future AD vehicles by using both general area of damage (GAD1) and impact angle (DOF1) and calculating injury risk for the combinations of these two factors (SAE J224, 1980). By this choice of analysis, evaluation of alternative seating positions and the effect of crash avoidance technologies on crash configurations can be performed.

\subsection{Type of crash}

The crashes were divided into seven types, according to the following definitions for an occupant sitting on the left side (driver). The definitions for the right seated occupant (passenger) are mirrored compared to the definitions below. The crash types are illustrated in Fig. 1 and in Appendix B.

- Side Near Side $($ DOF1 = 9, GAD1 = Left $)$

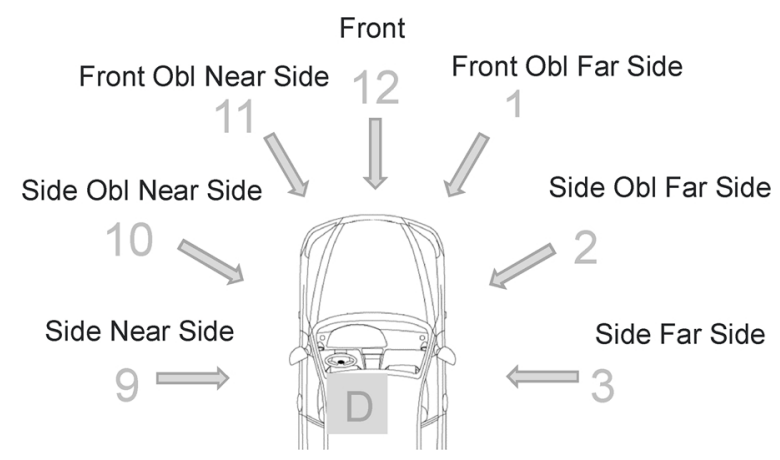

Fig. 1. Definition of crash types for an occupant sitting to the left. The definitions for an occupant sitting to the right are mirrored compared to these.
- Side Oblique Near Side (DOF1 = 10, GAD1 = Left, SHL1 = F, Y or P)

- Front Oblique Near Side $(\mathrm{DOF} 1=11$ or $12, \mathrm{GAD} 1=$ Front and SHL1 $=$ L or GAD1 $=$ Left and SHL $=$ F, P, Y or D)

- Front $(\mathrm{DOF} 1=11,12$ or $1, \mathrm{GAD}=$ Front, SHL1 = C, Z, Y or D)

- Front Oblique Far Side $(\mathrm{DOF} 1=12$ or $1, \mathrm{GAD} 1=$ Front and SHL1 $=$ R or GAD1 $=$ Right and SHL $=$ F, P, Y or D)

- Side Oblique Far Side (DOF1 = 2, GAD1 = Right, SHL1 = F, Y or P)

- Side Far Side (DOF1 = 3, GAD1 = Right)

\subsection{Injuries}

The analyses included only non-minor injuries (AIS2+) according to the AIS98 definitions. The injuries were analyzed in two steps. In the first step, a grouping of injuries was made according to the AIS body regions: head, face, neck, thorax, abdomen and pelvic contents, spine, upper extremities (including shoulder girdle) and lower extremities (including pelvis).

The risk of obtaining an AIS2 + injury in a specific body region in a specific type of crash was estimated as the quotient between the number of occupants who were injured in that body region in that type of crash (numerator), and the total number of occupants (injured or not), who had been involved in a crash of that specific type (denominator), as shown in Eq. 1. This risk was computed for both left seated and right seated occupants.

Injury risk of body partlcrash type

$=\frac{\text { No of occupants with injured body part } \mid \text { crash type }}{\text { All occupants } \mid \text { crashtype }}$

In a second step, each AIS body region was further divided into subgroups, like organs or organ systems, parts of the spine, and parts of the extremities. The complete list can be found in Table A1 in Appendix A. The basis for the subgroups was the 6-digit numerical identifier of the AIS98-code. However, as these codes are too detailed for the current HBMs, the codes were pooled into functional units in the following way:

- The upper extremity was divided into the following anatomical parts: the shoulder (including the scapula and the clavicle), the humerus, the elbow, the forearm, the wrist and hand (including fingers)

- The lower extremity was divided into the following anatomical parts: the hip (including the pelvis, the hip joint, and the proximal part of the femur), the femur shaft, the knee, the shaft of the lower leg, the ankle joint, and the foot (including toes).

The other body regions were divided into parts, which have or share similar types of function or are alike with respect to the effect of an injury. For example:

- The head was divided in external structures (skull bone and scalp) and internal structures (cerebrum, cerebellum, brain stem). Bleedings like epidural hemorrhage, subdural hemorrhage or subarachnoid hemorrhage were related to one of these internal structures when possible, as were diffuse axonal injuries.

- Concussion cannot be related to a specific part of the brain, why it was classified separately.

- The thorax was separated into the skeletal parts, the diaphragm, the major organs, and the major vessels.

- The abdomen and the pelvic contents were separated into the major organs and the major vessels.

- The face and the neck were separated into the skeletal parts and the organs.

- The spine was separated into the cervical spine, the thoracic spine, and the lumbar spine.

In this step, the three most frequent injuries were reported for the 
driver and passenger, each crash type and each body region.

Finally, to evaluate the influence of model year within the dataset (MY2000-MY2015) it was divided into two subgroups, MY2000-2006 and MY2007-2015. For this analysis, the number of crash directions were lumped reducing the number of crash directions from seven to three.

\section{Results}

The total number of crashes in the NASS/CDS database included 89 229 vehicles of model year 2000 through 2015. The number of cases meeting the inclusion criteria in this study was 13114 , and the number of occupants was 17935 . Of these, 12175 occupants (9 906 drivers and 2269 front seat passengers) were involved in crashes that could be classified in one of the seven crash types. Of these, 1832 occupants sustained at least one moderate or more serious (AIS2+) injury. Altogether, these 1832 occupants sustained 3262 AIS2+ injuries.

Frontal impacts caused $39 \%$ of the casualties, $17 \%$ were injured in frontal oblique impacts, $6 \%$ in side oblique impacts, and $5 \%$ in side impacts. The type of crash could not be classified in $33 \%$ of the cases due to lack of information of any of the variables: General Area of Damage (GAD), clock direction (DOF) or horizontal location of damage (SHL).

The risk of injury to a specific body region is shown in Table 1 for drivers and passengers and for the seven crash configurations.

In drivers, the risk of head injury was at least $2 \%$ in side near side, side oblique near side, and frontal oblique near side impacts. The risk of thoracic injury was at least $2 \%$ in side near side and in side oblique near side impacts. The risk of injury to the upper and lower extremities was at least $2 \%$ in frontal impacts and in side oblique near side impacts.

In passengers, the risk of head injury was at least $2 \%$ in frontal oblique near side impacts. The risk of thoracic injury was at least $2 \%$ in side near side and in frontal impacts. The risk of injury to the lower extremities was at least $2 \%$ in frontal impacts.

In Figs. 2-8, the body region injury risk from Table 1 is expanded to also include the distribution of the top three ranked injuries for each body region. All injuries sum up to $100 \%$ for each body region. However, as only the top three injuries are shown, these do not necessarily sum up to $100 \%$. The coloring of the occupants corresponds to the coloring in Table 1 (weighted injury risk) to highlight the body regions with highest injury risk.

For the drivers in side near side impacts, concussion was the most common injury of the head followed by subdural hemorrhage and cerebral injury (Fig. 2). For thorax, the most common injuries were rib fractures followed by injuries to the thorax cavity not further specified (NFS) and lung injuries. For the lower extremities, pelvis injuries dominated.

For passengers in side near side impacts, lungs followed by ribs and thorax cavity NFS were the most commonly injured thoracic structures.

For drivers in side oblique near side impacts, the most common head injuries were concussion followed by subdural hemorrhage and cerebral injuries (Fig. 3). For thorax, the most common injuries were rib fractures followed by injuries to the thorax cavity NFS and lung injuries. For the lower extremities, pelvis injuries dominated.

For passengers in frontal oblique near side impacts, the most common head injuries were concussion followed by subdural injuries and injuries to the skull base (Fig. 4).

For drivers and passengers in frontal impacts, the most frequent injuries to the lower extremities were ankle joint injuries followed by knee joint injuries. In addition, for the passengers, the most frequent thorax injury was sternum fractures followed by rib fractures and injuries to the thorax cavity NFS (Fig. 5).

In frontal oblique far side impacts, the injury risk was low for all body regions (Table 2). The injury risk for the different body parts was also low (Fig. 6).

For passengers in side oblique far side impacts, the most frequent injuries to the thorax were rib fractures and injuries to the diaphragm and major vessels (Fig. 7).

For passengers in side far side impacts, the most frequent injuries to the thorax were rib fractures and injuries to the thorax cavity NFS and the heart (Fig. 8).

When dividing the data into two groups: one with older vehicles MY2000-2006 (Table 2) and one with newer vehicles MY2007-2015 (Table 3) and lumping the crash directions into three groups, it can be observed that injuries to the lower extremity decreased somewhat for newer vehicles, while a clear trend cannot be observed for the other body regions.

Table 1

Weighted injury risk (AIS 2+) divided by body part and crash type for MY.2000-2015. (For interpretation of the references to colour in this table, the reader is referred to the web version of this article.)

Color coded according to risk; $0.1-0.6 \% \square$ 0.6-1.2\% $\square$ 1.2-1.8\% $\square$ 1.8-2.4\% $\square$ 2.4-3.0\% $\square$

$3.0-3.6 \%$

\begin{tabular}{|c|c|c|c|c|c|c|c|c|c|}
\hline & & Head & Face & Neck & Thorax & Abdomen & Spine & Ux & $\mathrm{Lx}$ \\
\hline \multirow{7}{*}{$\stackrel{\vec{D}}{\Delta}$} & Side NS & $2.3 \%$ & $0.1 \%$ & $0.0 \%$ & $2.0 \%$ & $1.1 \%$ & $1.0 \%$ & $0.9 \%$ & $1.8 \%$ \\
\hline & Side Obl NS & $2.8 \%$ & $0.1 \%$ & $0.0 \%$ & $2.0 \%$ & $0.5 \%$ & $0.9 \%$ & $2.2 \%$ & $3.0 \%$ \\
\hline & Frontal Obl NS & $2.5 \%$ & $0.1 \%$ & $0.0 \%$ & $0.9 \%$ & $0.2 \%$ & $0.6 \%$ & $1.2 \%$ & $1.6 \%$ \\
\hline & Frontal & $1.1 \%$ & $0.1 \%$ & $0.1 \%$ & $1.6 \%$ & $0.5 \%$ & $0.8 \%$ & $2.0 \%$ & $2.6 \%$ \\
\hline & Frontal Obl FS & $0.8 \%$ & $0.2 \%$ & $0.0 \%$ & $1.4 \%$ & $0.1 \%$ & $0.1 \%$ & $1.7 \%$ & $0.4 \%$ \\
\hline & Side Obl FS & $1.5 \%$ & $0.0 \%$ & $0.0 \%$ & $1.4 \%$ & $0.1 \%$ & $0.4 \%$ & $0.4 \%$ & $1.6 \%$ \\
\hline & Side FS & $1.0 \%$ & $0.1 \%$ & $0.0 \%$ & $0.5 \%$ & $0.2 \%$ & $0.3 \%$ & $0.2 \%$ & $0.5 \%$ \\
\hline \multirow{7}{*}{$\begin{array}{l}\text { 总 } \\
\text { c. }\end{array}$} & Side NS & $1.8 \%$ & $0.0 \%$ & $0.0 \%$ & $2.6 \%$ & $1.6 \%$ & $0.6 \%$ & $0.0 \%$ & $1.6 \%$ \\
\hline & Side Obl NS & $0.6 \%$ & $0.0 \%$ & $0.0 \%$ & $1.7 \%$ & $1.0 \%$ & $0.2 \%$ & $1.1 \%$ & $1.3 \%$ \\
\hline & Frontal Obl NS & $2.6 \%$ & $0.6 \%$ & $0.0 \%$ & $1.1 \%$ & $0.6 \%$ & $0.2 \%$ & $1.1 \%$ & $1.4 \%$ \\
\hline & Frontal & $0.9 \%$ & $0.1 \%$ & $0.0 \%$ & $3.0 \%$ & $0.5 \%$ & $0.8 \%$ & $2.6 \%$ & $2.2 \%$ \\
\hline & Frontal Obl FS & $0.2 \%$ & $0.0 \%$ & $0.0 \%$ & $0.4 \%$ & $0.5 \%$ & $0.1 \%$ & $0.9 \%$ & $0.2 \%$ \\
\hline & Side Obl FS & $1.9 \%$ & $0.2 \%$ & $0.0 \%$ & $1.9 \%$ & $0.4 \%$ & $0.6 \%$ & $0.4 \%$ & $1.0 \%$ \\
\hline & Side FS & $0.8 \%$ & $0.0 \%$ & $0.0 \%$ & $1.5 \%$ & $0.1 \%$ & $0.3 \%$ & $0.2 \%$ & $0.7 \%$ \\
\hline
\end{tabular}



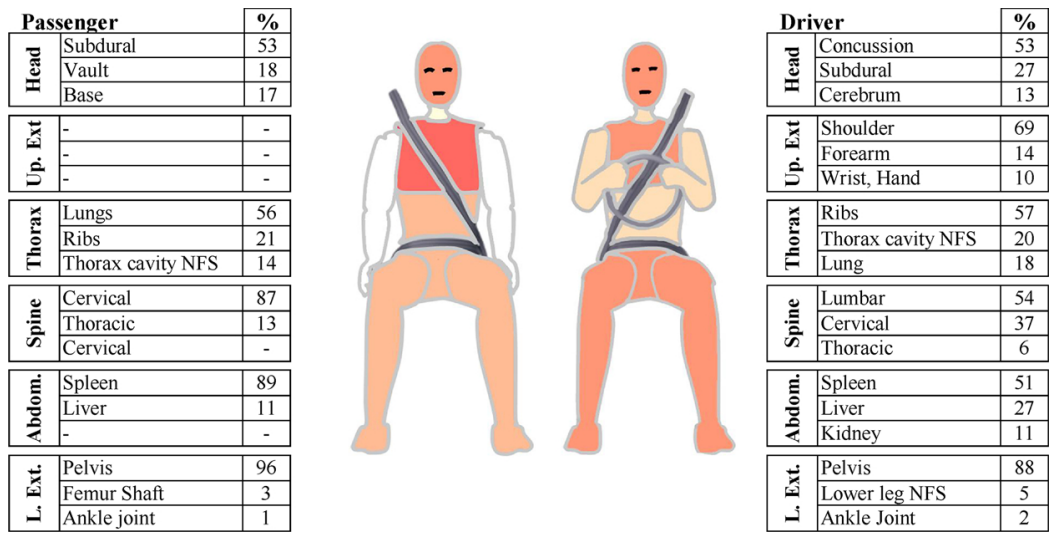

Fig. 2. The most common injuries in side near side impacts.

\section{Discussion}

In this study, the injured body regions and the specific injuries were analyzed and graded based on injury risk. The AIS98 system was used for injury classification, due to the fact that this was used for cases during 2000-2010. The frequency of the crash types was not taken into account. For example, the risk of an AIS2 + injury in frontal impacts was lower or equal to that in near side impacts for all body regions. However, as the number of frontal impacts was much greater (40\%) than in near side impacts ( $5 \%$ ), the number of AIS2 + injuries sustained in frontal impacts was much greater than in near side impacts. If the focus of the study had been the most frequently injured body regions, the results would have been concussive head injury, forearm injury, rib fractures, and injuries to the lower leg and foot sustained in frontal impacts. The frequency of injuries can be found in Appendix C. Since only the top three injuries were shown, there is a risk that an injury with a relatively high frequency can be missed. The injuries with the fourth highest frequency represented $10-16 \%$ of the injuries for respective load case and body region. However, all these injuries were present among the top three injuries for other load cases or positions. Thus, no injuries important for HBM development were missed.

In recent studies it was shown that the exposure can shift as vehicles become more automated. In a study by Klinich et al. (2016), the authors estimated that future vehicles with comprehensive crash avoidance technology can eliminate most frontal and roll-over crashes, while most side and rear-end impacts will remain, thus shifting the AIS2 + injury producing load cases towards side impacts. In another study, estimating the potential influence of all future advanced driver assistance systems
(ADAS) on future crash scenarios, four crash scenarios will represent 85 $\%$ of all AIS2 + injury crashes (Östling et al., 2018). These four crash scenarios are: A. Head-On; B. Turn Across Path, Initial Opposite Direction; C. Turn into Opposite Direction; and D. Straight Crossing Paths. For these crash configurations, the most common injuries in the future are estimated to be located to the head, thorax, and spine. However, these crash scenarios are not directly related to the crash types of this study.

Taking the expected future shift into account, this study suggests that the future development of human body models should focus on injuries seen in near side impacts. The anatomical structures and injuries that primary should be addressed are brain injuries (concussion), rib fractures and pelvis fractures. To address concussion, detailed brain models have already been developed (Kleiven, 2007; Sahoo et al., 2014). These models assess brain injuries by means of physical parameters such as stress or strain. Based on the stress or strain values, the risk of concussion is predicted using a brain tissue risk function. These models have been able to predict concussion by modelling various types of head impact resulting in concussion (Kleiven, 2007; Sahoo et al., 2014) and appear to be applicable tools to assess brain injuries. However, as concussion cannot be related to a specific part of the brain, the HBMs should also include the brain stem and part of the spinal cord.

It was shown that the risk of an occupant to sustain rib fractures in a frontal impact can be predicted by the strain in the ribs (Iraeus and Lindquist, 2015). Fracture prediction using strain is independent of loading direction. However, validation of the human body model has to be expanded to include oblique and side loading before the model can predict rib fracture, regardless of the direction of impact. In addition,
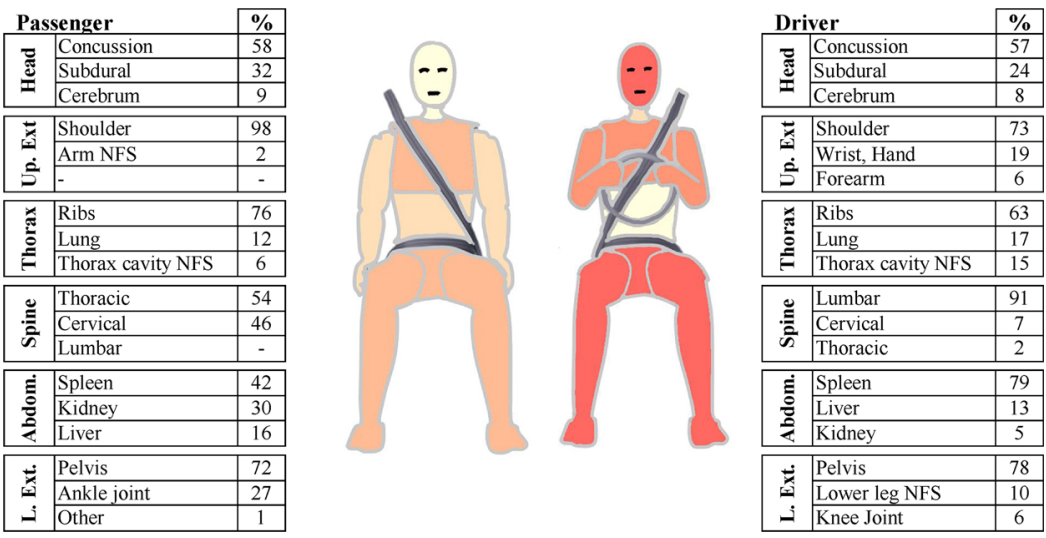

Fig. 3. The most common injuries in side oblique near side impacts. 

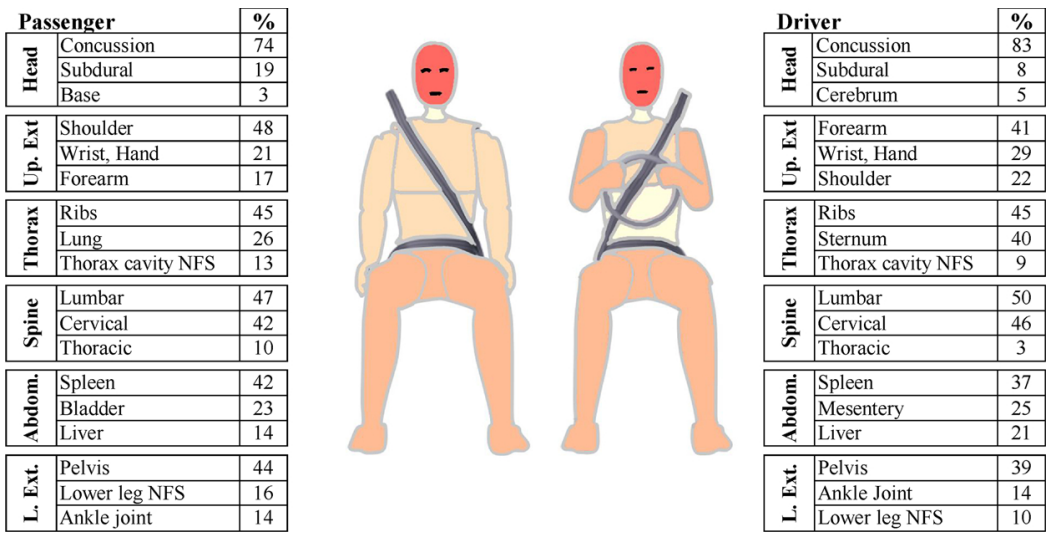

Fig. 4. The most common injuries in frontal oblique near side impacts.
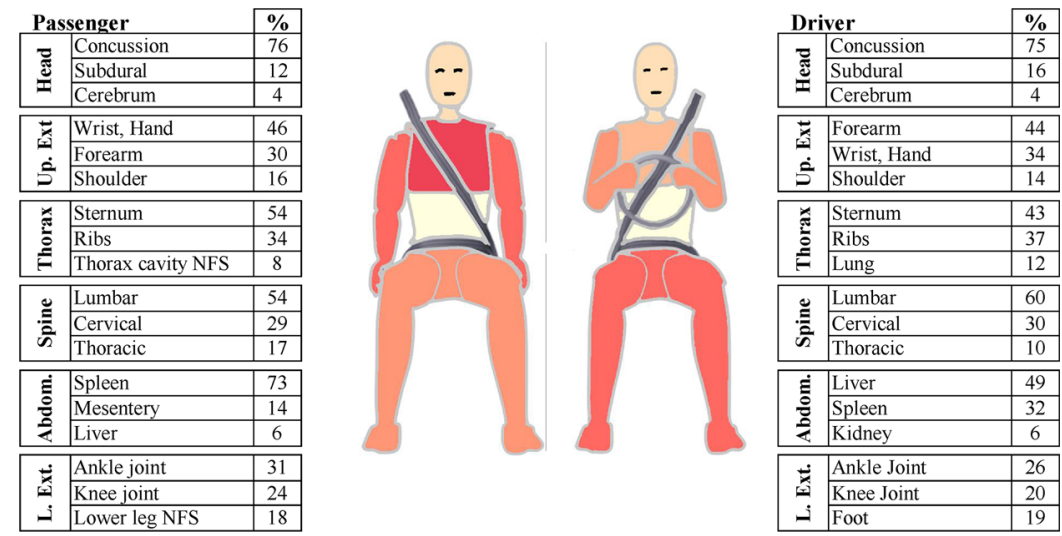

Fig. 5. The most common injuries in frontal impacts.
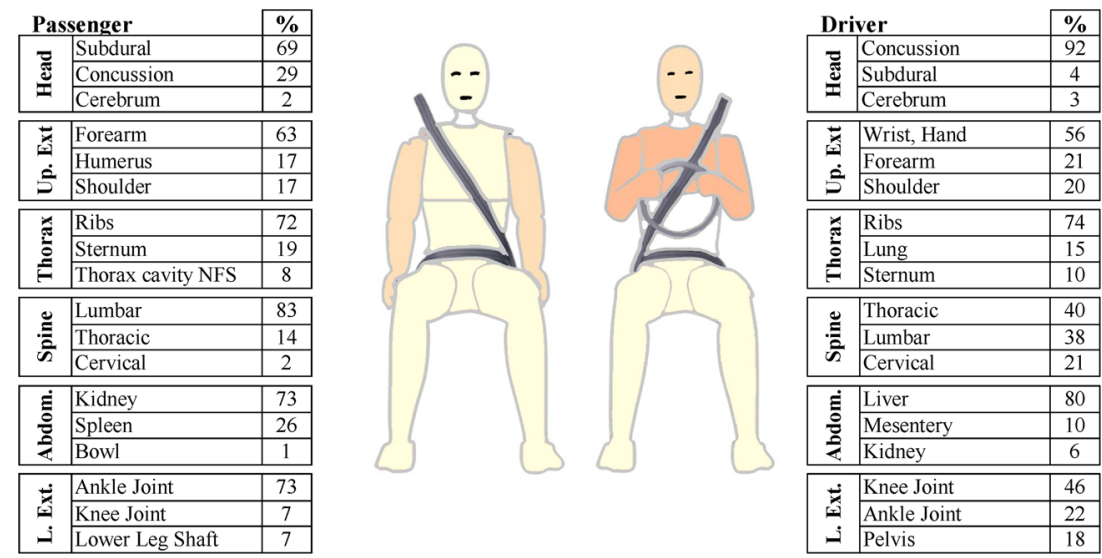

Fig. 6. The most common injuries in frontal oblique far side impacts.

the increased injury risk from combined loading of the chest such as simultaneous load on the chest from the front and side can be accounted for.

Few published studies exist with similar scope as the current study. However, in a NASS-CDS 2000-2011 study of restrained occupants, it was found that the lower extremity had the highest risk of AIS2+ injury (24.6\%), followed by the upper extremity $(16.0 \%)$, thorax $(12.4 \%)$, head (7.6\%), spine (4.6\%), abdomen (3.4\%) and face (0.6\%) (Weaver et al., 2015). These results are similar to that of the current study if exposure is also considered, or in other words, these are the body parts most commonly injured in frontal impacts. Another study on the Mortality Risk Ratio (MRR), which measures the mortality associated with injuries, showed that the most common AIS2 + head injury was unconsciousness less than one hour (AIS2) with a mortality risk of $<0.1$ $\%$ (Weaver et al., 2013). The most common AIS2 + lower extremity injury was a closed pelvis fracture (AIS2) and the most common AIS2 + abdominal injury was a spleen laceration (AIS2), both with a MRR of 6-7 \%. The most common AIS2 + chest injury was a unilateral lung contusion (AIS3) with an MRR of $6.4 \%$.

In order to get a dataset large enough to analyze according to the 

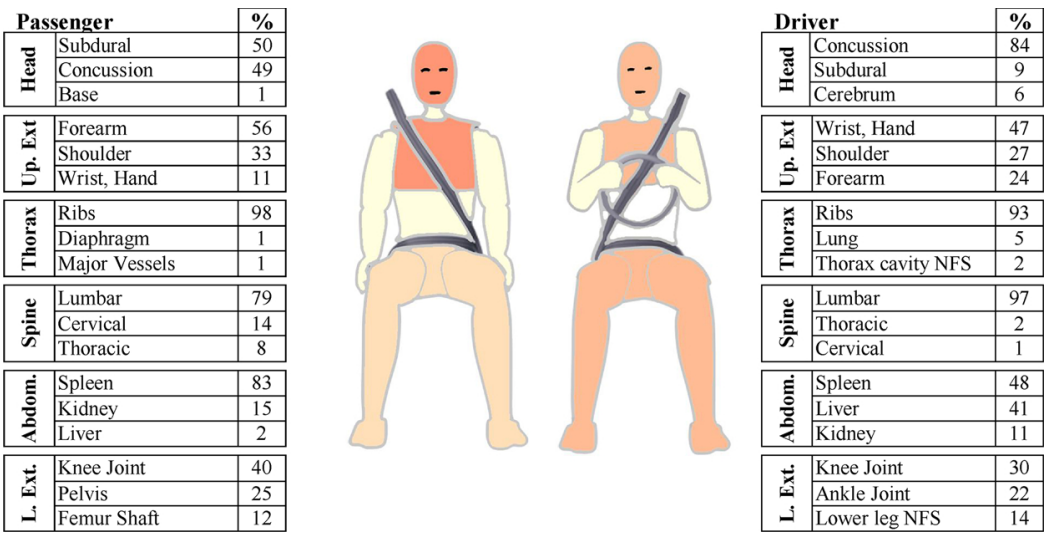

Fig. 7. The most common injuries in side oblique far side impacts.
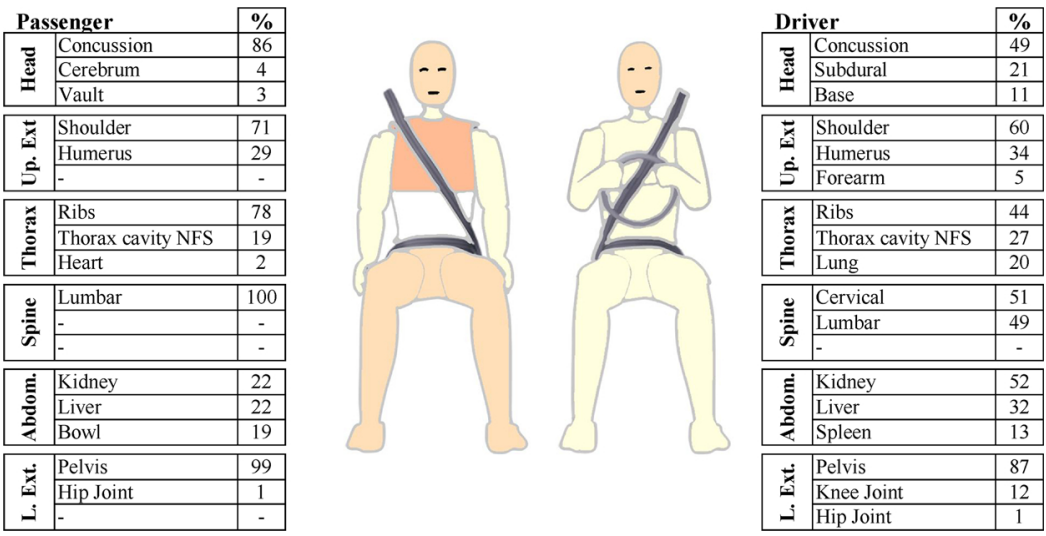

Fig. 8. The most common injuries in side far side impacts.

Table 2

Weighted injury risk (AIS 2+) divided by body part and crash type for MY.2000-2006. (For interpretation of the references to colour in this table, the reader is referred to the web version of this article.)

Color coded according to risk; $0.1-0.6 \% \square \quad 0.6-1.2 \% \square \quad 1.2-1.8 \% \square \quad 1.8-2.4 \% \square$ 2.4-3.0\%

\begin{tabular}{|c|c|c|c|c|c|c|c|c|c|}
\hline & & Head & Face & Neck & Thorax & Abdomen & Spine & $\mathrm{Ux}$ & $\mathrm{Lx}$ \\
\hline \multirow{3}{*}{ D } & Side NS incl. obl. & $2.5 \%$ & $0.2 \%$ & $0.0 \%$ & $2.3 \%$ & $0.9 \%$ & $1.0 \%$ & $1.8 \%$ & $2.7 \%$ \\
\hline & Frontal incl. obl. & $1.0 \%$ & $0.1 \%$ & $0.0 \%$ & $1.3 \%$ & $0.4 \%$ & $0.4 \%$ & $1.7 \%$ & $2.4 \%$ \\
\hline & Side FS incl. obl. & $1.8 \%$ & $0.1 \%$ & $0.0 \%$ & $1.1 \%$ & $0.2 \%$ & $0.4 \%$ & $0.4 \%$ & $1.4 \%$ \\
\hline
\end{tabular}

Table 3

Weighted injury risk (AIS 2+) divided by body part and crash type for MY.2007-2015. (For interpretation of the references to colour in this table, the reader is referred to the web version of this article.)

Color coded according to risk; $0.1-0.6 \% \square$ 0.6-1.2\% $\square$ 1.2-1.8\% $\square$ 1.8-2.4\% $\square$ 2.4-3.0\% $\square$

\begin{tabular}{|c|c|c|c|c|c|c|c|c|c|}
\hline & & Head & Face & Neck & Thorax & Abdomen & Spine & Ux & $\mathrm{Lx}$ \\
\hline \multirow{3}{*}{$\stackrel{\bar{D}}{D}$} & Side NS incl. obl. & $2.7 \%$ & $0.0 \%$ & $0.0 \%$ & $1.3 \%$ & $0.7 \%$ & $1.3 \%$ & $0.8 \%$ & $1.6 \%$ \\
\hline & Frontal incl. obl. & $2.0 \%$ & $0.1 \%$ & $0.2 \%$ & $1.8 \%$ & $0.3 \%$ & $1.3 \%$ & $2.1 \%$ & $1.3 \%$ \\
\hline & Side FS incl. obl. & $0.1 \%$ & $0.0 \%$ & $0.0 \%$ & $0.7 \%$ & $0.0 \%$ & $0.3 \%$ & $0.2 \%$ & $0.6 \%$ \\
\hline
\end{tabular}


method in this study, vehicles all way back to model year 2000 were included. Year 2000 was chosen as Euro NCAP was phased in from 1997 to 2000 (van Ratingen et al., 2016). Euro NCAP was driving significant modifications to the vehicle structures and safety systems. As passive safety is gradually progressing, some of the injuries seen in early 2000 cars might not be present in modern cars. Due to the fact that no clear trend was observed when the weighted data was divided into two groups the complete data set was considered valid for the complete model year span used in the analysis.

For drivers, the head followed by the thorax were the most frequently injured body regions. The most common head injuries were concussion and subdural hemorrhage. The most common thoracic injuries were related to the ribs, the lungs and the thorax cavity NFS. For passengers, the thorax followed by the head were the most frequently injured body regions. The most common thoracic injuries were related to the lungs, the ribs and the sternum. The most common head injuries were concussion and subdural hemorrhage.

The GHBMC head model was validated for head impacts by means of real world head impacts (Mao et al., 2013). However, tissue level criteria were only proposed for head fracture and brain contusion. Criteria for concussion and subdural hemorrhage were not assessed by Mao et al. (2013). The GHBMC detailed human body occupant model (M50-O; Ver. 4.4) was used to study rib failure prediction differences when examined deterministically and probabilistically (Guleyupoglu et al., 2018). However, the capability to predict the risk of rib fracture, sternum fracture or lung injury with the GHBMC model was not validated. Therefore, the current study can be used for prioritizing development of the injury prediction capability of the GHBMC and other human body models.

To develop more valid human body models, further studies should be made, which include data that have a great influence on the accident outcome such as the crash severity, the age of the occupant, and the properties of the restraint system.

\section{Limitations}

The major limitation of the study is the low number of cases and injuries in some crash types, which gives uncertainties in the risk estimation and for the distribution of specific injuries. This is particularly the case for passengers. In the unweighted database, there were 146 passengers with head injuries in near side impacts of which 21 sustained a concussion. With so few cases, the weighting of the results can change the risk estimates as well as the order of the most frequent injuries significantly. However, for the boxes with high risk: head, thorax, upper and lower extremity, the number of raw injury counts was high, which leads to stable risk evaluations. For the top ten boxes for the driver, the box with least number of cases was the upper extremity box for side oblique near side with 39 cases. It was considered enough for reliable risk estimation.
In addition, there is also an uncertainty in risk estimation related to the NASS/CDS inclusion criteria. The risk estimates in this study are computed and based on the NASS inclusion criteria. This means that the vehicle has to be towed away from the scene of the crash. Different levels of crash severity for different load cases can be necessary for it to be a tow away crash and included in the NASS database. That can result in that one crash direction can be overrepresented over another in the risk estimation.

Another limitation is that AIS1 injuries were excluded. One reason for this is that AIS1 injuries are underreported in the NASS database, because many of those with only AIS1 injuries never seek hospital care, and they are therefore not included in the NASS database. However, in future studies AIS1 + injuries resulting in long term consequences should be included.

\section{Conclusions}

Taking the predictions for future crash scenarios of $\mathrm{AD}$ vehicles into account, the HBM body regions which should be focused on is the head, the thorax and the lower extremities in side impacts, and the specific injuries are concussion, rib and pelvic fractures. For non-AD vehicles injuries to the lower extremities, like knee and ankle joint injuries, are also in focus.

\section{CRediT authorship contribution statement}

Bengt Pipkorn: Conceptualization, Methodology, Writing - original draft, Writing - review \& editing, Project administration. Johan Iraeus: Conceptualization, Methodology, Writing - original draft, Writing - review \& editing, Visualization. Mats Lindkvist: Methodology, Resources. Pradeep Puthan: Formal analysis, Visualization. Olle Bunketorp: Conceptualization, Methodology, Writing - original draft, Writing - review \& editing.

\section{Declaration of Competing Interest}

The authors declare that they have no known competing financial interests or personal relationships that could have appeared to influence the work reported in this paper.

\section{Acknowledgements}

The project was carried out at SAFER -Vehicle and Traffic Safety Centre at Chalmers, Sweden, and financed by the industrial project partners, SAFER and FFI (Strategic Vehicle Research and Innovation), VINNOVA, the Swedish Transport Administration, the Swedish Energy Agency. The project partners are Chalmers University of Technology, Autoliv Research, Sahlgrenska University Hospital and Volvo Cars. 


\section{Appendix A}

Table A1

Body regions and parts of region/types of injury used in the analyses.

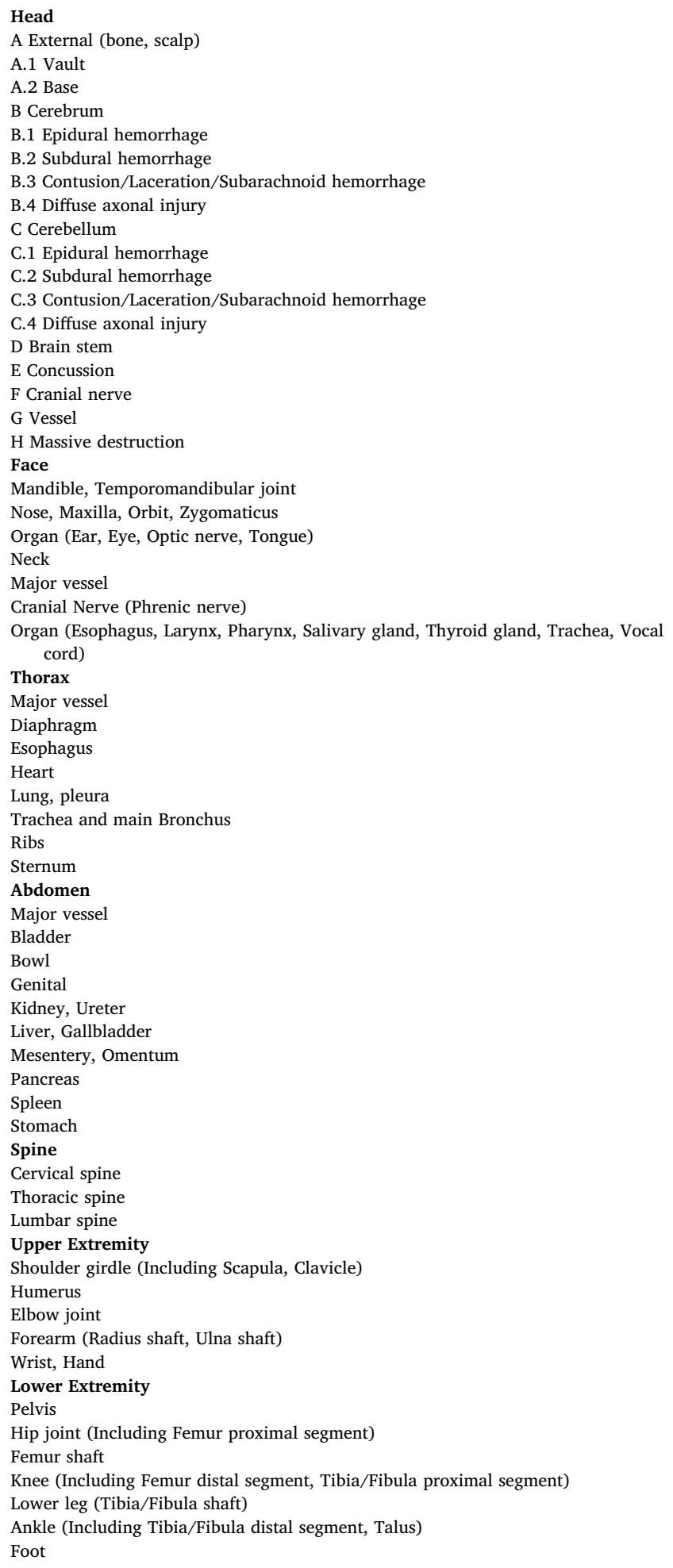




\section{Appendix B}

See Fig. B1.

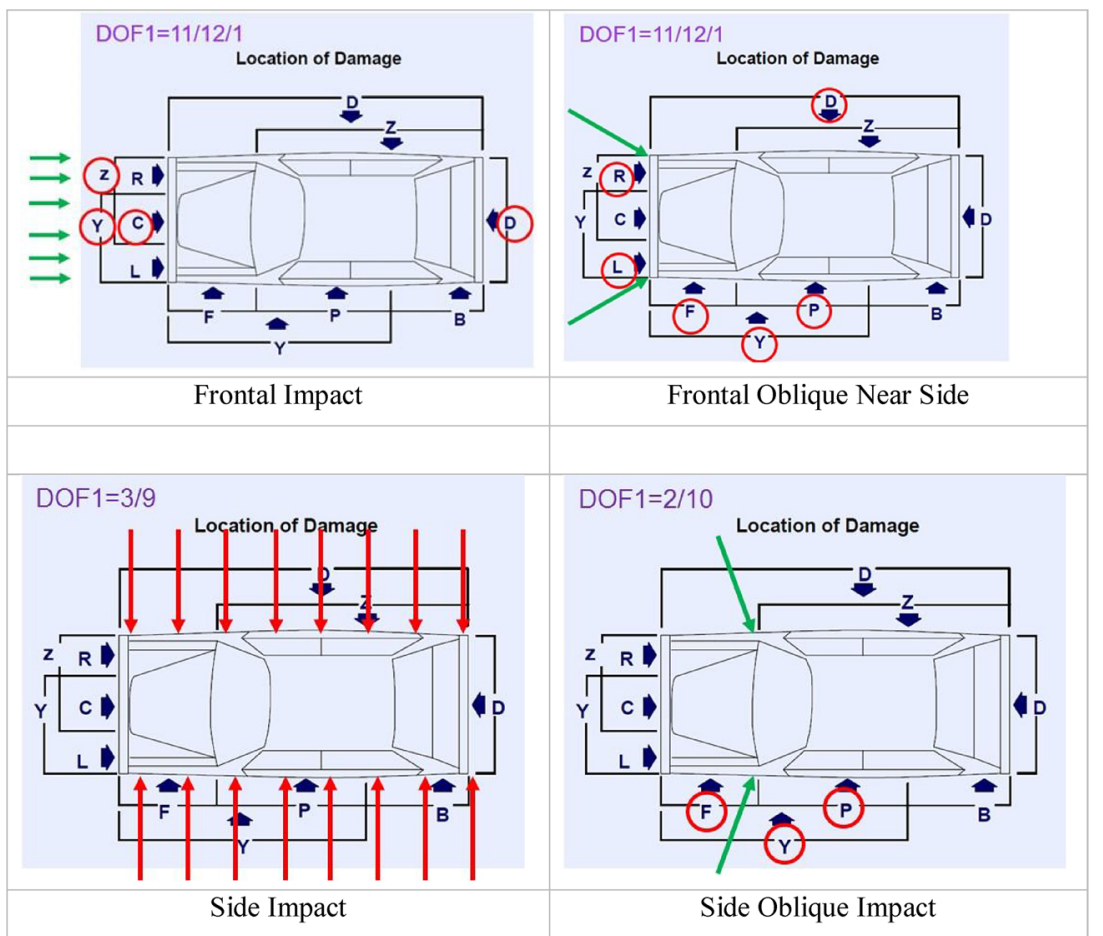

Fig. B1. Filtering criteria for each load case as per Collision Deformation Classification (SAE J 224 standard)". The green arrows show the selected loading directions. Red arrows indicate all the loads/crashes from the respective directions (here both sides). (For interpretation of the references to colour in this figure legend, the reader is referred to the web version of this article.)

\section{Appendix C}

See Table C1.

Table C1

Weighted Frequency of Injured Body Regions (AIS 2+) and Crash Configurations.

\begin{tabular}{|c|c|c|c|c|c|c|c|c|c|}
\hline & & Head & Face & Neck & Thorax & Abdomen & Spine & $\mathrm{Ux}$ & $\mathrm{Lx}$ \\
\hline \multirow[t]{7}{*}{ Driver } & Side NS & 4557 & 286 & 0 & 3986 & 2213 & 2054 & 1790 & 3696 \\
\hline & Side Obl NS & 5344 & 216 & 0 & 3902 & 999 & 1683 & 4137 & 5671 \\
\hline & Frontal Obl NS & 10422 & 438 & 22 & 5532 & 1143 & 3740 & 7566 & 10090 \\
\hline & Frontal & 27377 & 3174 & 1917 & 37940 & 11687 & 19167 & 48752 & 54462 \\
\hline & Frontal Obl FS & 4660 & 995 & 0 & 3548 & 411 & 546 & 5369 & 2603 \\
\hline & Side Obl FS & 2724 & 0 & 0 & 2434 & 100 & 688 & 695 & 2922 \\
\hline & Side FS & 1436 & 139 & 0 & 708 & 296 & 415 & 333 & 772 \\
\hline \multirow[t]{7}{*}{ Pass } & Side NS & 715 & 0 & 8 & 1020 & 617 & 231 & 0 & 645 \\
\hline & Side Obl NS & 206 & 0 & 0 & 629 & 379 & 71 & 408 & 456 \\
\hline & Frontal Obl NS & 2800 & 635 & 0 & 1224 & 665 & 223 & 1233 & 1503 \\
\hline & Frontal & 4063 & 428 & 94 & 13230 & 2100 & 3387 & 6192 & 9728 \\
\hline & Frontal Obl FS & 274 & 0 & 0 & 481 & 578 & 61 & 1117 & 288 \\
\hline & Side Obl FS & 682 & 71 & 0 & 712 & 149 & 220 & 156 & 349 \\
\hline & Side FS & 428 & 20 & 0 & 748 & 28 & 136 & 127 & 364 \\
\hline \multicolumn{10}{|l|}{ HEAD } \\
\hline \multicolumn{5}{|c|}{ Frontal Impact } & \multicolumn{3}{|l|}{ Driver } & \multicolumn{2}{|c|}{ Passenger } \\
\hline \multicolumn{5}{|c|}{ Base Fractures } & \multicolumn{3}{|l|}{4420} & \multicolumn{2}{|c|}{621} \\
\hline \multicolumn{5}{|c|}{ Brain Stem } & \multicolumn{3}{|l|}{2340} & \multicolumn{2}{|c|}{1195} \\
\hline \multicolumn{5}{|c|}{ Cerebrum Contusion/Intracerebral Injury } & \multicolumn{3}{|l|}{14004} & \multicolumn{2}{|c|}{1810} \\
\hline \multicolumn{5}{|c|}{ Cerebrum Diffuse Axonal Injury } & \multicolumn{3}{|l|}{235} & \multicolumn{2}{|c|}{338} \\
\hline \multicolumn{5}{|c|}{ Concussion } & \multicolumn{3}{|l|}{247127} & \multicolumn{2}{|c|}{37691} \\
\hline \multicolumn{5}{|c|}{ Cranial Nerve } & \multicolumn{3}{|l|}{1707} & \multicolumn{2}{|c|}{0} \\
\hline \multicolumn{5}{|c|}{ Epidural Injury } & \multicolumn{3}{|l|}{69} & \multicolumn{2}{|l|}{0} \\
\hline \multicolumn{5}{|c|}{ Massive Destruction } & \multicolumn{3}{|l|}{144} & \multicolumn{2}{|c|}{0} \\
\hline
\end{tabular}


Table C1 (continued)

\begin{tabular}{|c|c|c|}
\hline HEAD & & \\
\hline Not classified & 202 & 0 \\
\hline Scalp & 121 & 0 \\
\hline Subdural Injury & 53532 & 5956 \\
\hline Vault Fractures & 5322 & 1775 \\
\hline Hematoma NFS & 147 & 0 \\
\hline Cerbebellum Contusion/Intracerebellar Injury & 217 & 0 \\
\hline Cerbebellum Contusion/Intracerebellar & 26 & 0 \\
\hline Vessel & 28 & 4 \\
\hline Frontal Oblique Far Side & Driver & Passenger \\
\hline Cerebrum Contusion/Intracerebral Injury & 1400 & 82 \\
\hline Concussion & 47074 & 1009 \\
\hline Subdural Injury & 2050 & 2376 \\
\hline Vault Fractures & 291 & 0 \\
\hline Frontal Oblique Near Side & Driver & Passenger \\
\hline Concussion & 89396 & 23335 \\
\hline Subdural Injury & 14498 & 5967 \\
\hline Cerebrum Contusion/Intracerebral Injury & 9529 & 835 \\
\hline Vault Fractures & 2940 & 0 \\
\hline Base Fractures & 1350 & 973 \\
\hline Brain Stem & 614 & 193 \\
\hline Hematoma NFS & 223 & 141 \\
\hline Scalp & 163 & 141 \\
\hline Not classified & 96 & 0 \\
\hline Cranial Nerve & 125 & 0 \\
\hline Epidural Injury & 78 & 0 \\
\hline Cerbebellum Contusion/Intracerebellar Injury & 5 & 0 \\
\hline Side Impact Far Side & Driver & Passenger \\
\hline Base Fractures & 2630 & 158 \\
\hline Brain Stem & 65 & 0 \\
\hline Cerbebellum Contusion/Intracerebellar Injury & 0 & 56 \\
\hline Cerebrum Contusion/Intracerebral Injury & 2137 & 227 \\
\hline Cerebrum Diffuse Axonal Injury & 19 & 0 \\
\hline Concussion & 11803 & 4559 \\
\hline Cranial Nerve & 86 & 0 \\
\hline Epidural Injury & 16 & 0 \\
\hline Subdural Injury & 4940 & 118 \\
\hline Vault Fractures & 2194 & 178 \\
\hline Side Impact Near Side & Driver & Passenger \\
\hline Base Fractures & 149 & 4317 \\
\hline Brain Stem & 523 & 116 \\
\hline Cerbebellum Contusion/Intracerebellar & 4 & 0 \\
\hline Cerbebellum Contusion/Intracerebellar Injury & 4 & 0 \\
\hline Cerebrum Contusion/Intracerebral Injury & 8225 & 83 \\
\hline Cerebrum Diffuse Axonal Injury & 505 & 0 \\
\hline Concussion & 34370 & 2995 \\
\hline Hematoma NFS & 404 & 0 \\
\hline Massive Destruction & 0 & 16 \\
\hline Subdural Injury & 17596 & 13588 \\
\hline Vault Fractures & 3047 & 4726 \\
\hline Side Oblique Far Side & Driver & Passenger \\
\hline Base Fractures & 0 & 72 \\
\hline Brain Stem & 89 & 72 \\
\hline Cerbebellum Contusion/Intracerebellar & 0 & 10 \\
\hline Cerebrum Contusion/Intracerebral Injury & 2099 & 0 \\
\hline Concussion & 30527 & 5826 \\
\hline Cranial Nerve & 102 & 0 \\
\hline Subdural Injury & 3411 & 5943 \\
\hline Vault Fractures & 55 & 0 \\
\hline Side Oblique Near Side & Driver & Passenger \\
\hline Base Fractures & 1214 & 0 \\
\hline Brain Stem & 1639 & 0 \\
\hline Cerbebellum Contusion/Intracerebellar & 46 & 0 \\
\hline Cerebrum Contusion/Intracerebral Injury & 6182 & 191 \\
\hline Cerebrum Diffuse Axonal Injury/Concussion & 177 & 0 \\
\hline Concussion & 45083 & 1217 \\
\hline Subdural Injury & 19039 & 676 \\
\hline Vault Fractures & 5826 & 0 \\
\hline \multicolumn{3}{|l|}{ FACE } \\
\hline Frontal Impact & Driver & Passenger \\
\hline Face Laceration & 1706 & 0 \\
\hline Mandible & 642 & 0 \\
\hline Maxilla & 2721 & 847 \\
\hline Nose & 5904 & 423 \\
\hline
\end{tabular}


Table C1 (continued)

\begin{tabular}{|c|c|c|}
\hline FACE & & \\
\hline Orbita & 5501 & 2312 \\
\hline Organ & 140 & 0 \\
\hline Other & 63 & 0 \\
\hline Tempomandibular joint & 1721 & 254 \\
\hline Zygoma & 1126 & 0 \\
\hline Not Available & 22 & 0 \\
\hline Frontal Oblique Far Side & Driver & Passenger \\
\hline Organ & 0 & 0 \\
\hline Other & 0 & 0 \\
\hline Mandible & 0 & 0 \\
\hline Maxilla & 8053 & 0 \\
\hline Nose & 25 & 0 \\
\hline Orbita & 599 & 0 \\
\hline Tempomandibluar joint & 0 & 0 \\
\hline Zygoma & 0 & 0 \\
\hline Face Laceration & 0 & 0 \\
\hline Frontal Oblique Near Side & Driver & Passenger \\
\hline Organ & 0 & 0 \\
\hline Other & 0 & 0 \\
\hline Mandible & 110 & 0 \\
\hline Maxilla & 1983 & 4570 \\
\hline Nose & 246 & 0 \\
\hline Orbita & 1125 & 1488 \\
\hline Tempomandibluar joint & 0 & 0 \\
\hline Zygoma & 171 & 3369 \\
\hline Face Laceration & 68 & 235 \\
\hline Side Impact Far Side & Driver & Passenger \\
\hline Organ & 0 & 0 \\
\hline Other & 198 & 0 \\
\hline Mandible & 0 & 0 \\
\hline Maxilla & 0 & 178 \\
\hline Nose & 697 & 0 \\
\hline Orbita & 594 & 237 \\
\hline Tempomandibluar joint & 0 & 0 \\
\hline Zygoma & 0 & 99 \\
\hline Face Laceration & 0 & 0 \\
\hline Side Impact Near Side & Driver & Passenger \\
\hline Organ & 0 & 0 \\
\hline Other & 0 & 0 \\
\hline Mandible & 0 & 0 \\
\hline Maxilla & 597 & 0 \\
\hline Nose & 0 & 0 \\
\hline Orbita & 2146 & 0 \\
\hline Tempomandibular joint & 11 & 0 \\
\hline Zygoma & 505 & 0 \\
\hline Face Laceration & 0 & 0 \\
\hline Side Oblique Far Side & Driver & Passenger \\
\hline Organ & 0 & 0 \\
\hline Other & 0 & 0 \\
\hline Mandible & 0 & 21 \\
\hline Maxilla & 0 & 551 \\
\hline Nose & 0 & 0 \\
\hline Orbita & 0 & 0 \\
\hline Tempomandibluar joint & 0 & 0 \\
\hline Zygoma & 0 & 0 \\
\hline Face Laceration & 0 & 306 \\
\hline Side Oblique Near Side & Driver & Passenger \\
\hline Organ & 0 & 0 \\
\hline Other & 0 & 0 \\
\hline Mandible & 215 & 0 \\
\hline Maxilla & 646 & 0 \\
\hline Nose & 0 & 0 \\
\hline Orbita & 380 & 0 \\
\hline Tempomandibluar joint & 0 & 0 \\
\hline Zygoma & 0 & 0 \\
\hline Face Laceration & 403 & 0 \\
\hline \multicolumn{3}{|l|}{ NECK } \\
\hline Frontal Impact & Driver & Passenger \\
\hline Hyoid Fracture & 417 & 339 \\
\hline Laceration & 1707 & 0 \\
\hline Organ & 27 & 94 \\
\hline Vessel & 89 & 0 \\
\hline Frontal Oblique Near Side & Driver & Passenger \\
\hline
\end{tabular}


Table C1 (continued)

\begin{tabular}{|c|c|c|}
\hline NECK & & \\
\hline Hyoid Fracture & 87 & 0 \\
\hline Laceration & 0 & 0 \\
\hline Organ & 29 & 0 \\
\hline Vessel & 0 & 0 \\
\hline Side Impact Near Side & Driver & Passenger \\
\hline Hyoid Fracture & 0 & 33 \\
\hline Laceration & 0 & 0 \\
\hline Organ & 0 & 0 \\
\hline Vessel & 0 & 0 \\
\hline \multicolumn{3}{|l|}{ THORAX } \\
\hline Frontal Impact & Driver & Passenger \\
\hline Diaphragma & 3037 & 329 \\
\hline Esophagus & 59 & 0 \\
\hline Esphagus & 13 & 0 \\
\hline Heart & 4786 & 65 \\
\hline Lungs & 66500 & 6771 \\
\hline Major Vessels & 3368 & 218 \\
\hline Rib Fractures & 198739 & 62111 \\
\hline Sternum Fractures & 234341 & 99663 \\
\hline Thoracic Cavity Injury NFS & 28995 & 14854 \\
\hline Trachea and Main Bornchus NFS & 25 & 245 \\
\hline Frontal Oblique Far Side & Driver & Passenger \\
\hline Major Vessels & 0 & 0 \\
\hline Diaphragma & 291 & 0 \\
\hline Esophagus & 0 & 0 \\
\hline Heart & 0 & 0 \\
\hline Lungs & 6919 & 0 \\
\hline Thoracic Cavity Injury NFS & 0 & 682 \\
\hline Trachea and Main Bornchus NFS & 0 & 0 \\
\hline Rib Fractures & 35085 & 6014 \\
\hline Sternum Fractures & 4809 & 1611 \\
\hline Frontal Oblique Near Side & Driver & Passenger \\
\hline Major Vessels & 293 & 1205 \\
\hline Diaphragma & 2004 & 1043 \\
\hline Esophagus & 0 & 0 \\
\hline Heart & 623 & 317 \\
\hline Lungs & 15516 & 7914 \\
\hline Thoracic Cavity Injury NFS & 7581 & 3896 \\
\hline Trachea and Main Bornchus NFS & 0 & 0 \\
\hline Rib Fractures & 31646 & 13408 \\
\hline Sternum Fractures & 15664 & 2232 \\
\hline Side Impact Far Side & Driver & Passenger \\
\hline Major Vessels & 205 & 0 \\
\hline Diaphragma & 86 & 0 \\
\hline Esophagus & 0 & 0 \\
\hline Heart & 760 & 168 \\
\hline Lungs & 2877 & 140 \\
\hline Thoracic Cavity Injury NFS & 3948 & 2090 \\
\hline Trachea and Main Bornchus NFS & 0 & 0 \\
\hline Rib Fractures & 6407 & 8595 \\
\hline Sternum Fractures & 124 & 0 \\
\hline Side Impact Near Side & Driver & Passenger \\
\hline Major Vessels & 447 & 607 \\
\hline Diaphragma & 1308 & 95 \\
\hline Esophagus & 39 & 0 \\
\hline Heart & 122 & 544 \\
\hline Lungs & 12415 & 9075 \\
\hline Thoracic Cavity Injury NFS & 14054 & 2300 \\
\hline Trachea and Main Bornchus NFS & 21 & 0 \\
\hline Rib Fractures & 39460 & 3427 \\
\hline Sternum Fractures & 1539 & 90 \\
\hline Side Oblique Far Side & Driver & Passenger \\
\hline Major Vessels & 0 & 62 \\
\hline Diaphragma & 0 & 120 \\
\hline Esophagus & 0 & 0 \\
\hline Heart & 0 & 0 \\
\hline Lungs & 1565 & 10 \\
\hline Thoracic Cavity Injury NFS & 629 & 0 \\
\hline Trachea and Main Bornchus NFS & 0 & 0 \\
\hline Rib Fractures & 29379 & 8469 \\
\hline Sternum Fractures & 69 & 0 \\
\hline Side Oblique Near Side & Driver & Passenger \\
\hline Major Vessels & 625 & 191 \\
\hline
\end{tabular}


Table C1 (continued)

\begin{tabular}{|c|c|c|}
\hline \multicolumn{3}{|l|}{ THORAX } \\
\hline Diaphragma & 494 & 0 \\
\hline Esophagus & 0 & 0 \\
\hline Heart & 436 & 94 \\
\hline Lungs & 10452 & 1082 \\
\hline Thoracic Cavity Injury NFS & 9134 & 563 \\
\hline Trachea and Main Bornchus NFS & 0 & 0 \\
\hline Rib Fractures & 37694 & 6683 \\
\hline Sternum Fractures & 1173 & 202 \\
\hline \multicolumn{3}{|l|}{ ABDOMEN } \\
\hline Frontal Impact & Driver & Passenger \\
\hline Bladder & 1153 & 0 \\
\hline Bowl & 5074 & 1357 \\
\hline Genitials & 304 & 0 \\
\hline Kidney & 6887 & 388 \\
\hline Liver & 53471 & 1421 \\
\hline Major Vessels & 606 & 24 \\
\hline Mesentery & 5194 & 3508 \\
\hline Not classified & 32 & 0 \\
\hline Other & 62 & 0 \\
\hline Pancreas & 1285 & 8 \\
\hline Spleen & 34904 & 18270 \\
\hline Stomach & 8 & 155 \\
\hline Frontal Oblique Far Side & Driver & Passenger \\
\hline Bladder & 0 & 0 \\
\hline Bowl & 61 & 24 \\
\hline Genitials & 0 & 0 \\
\hline Kidney & 259 & 1891 \\
\hline Liver & 3361 & 0 \\
\hline Major Vessels & 0 & 0 \\
\hline Mesentery & 416 & 0 \\
\hline Pancreas & 0 & 0 \\
\hline Spleen & 112 & 680 \\
\hline Stomach & 0 & 0 \\
\hline Frontal Oblique Near Side & Driver & Passenger \\
\hline Bladder & 817 & 1259 \\
\hline Bowl & 0 & 598 \\
\hline Genitials & 0 & 0 \\
\hline Kidney & 929 & 70 \\
\hline Liver & 2181 & 767 \\
\hline Major Vessels & 113 & 35 \\
\hline Mesentery & 2576 & 352 \\
\hline Pancreas & 0 & 0 \\
\hline Spleen & 3873 & 2335 \\
\hline Stomach & 0 & 0 \\
\hline Other & 0 & 193 \\
\hline Side Impact Far Side & Driver & Passenger \\
\hline Bladder & 53 & 0 \\
\hline Bowl & 0 & 168 \\
\hline Genitials & 0 & 0 \\
\hline Kidney & 802 & 196 \\
\hline Liver & 495 & 196 \\
\hline Major Vessels & 0 & 0 \\
\hline Mesentery & 0 & 140 \\
\hline Pancreas & 0 & 56 \\
\hline Spleen & 198 & 140 \\
\hline Stomach & 0 & 0 \\
\hline Side Impact Near Side & Driver & Passenger \\
\hline Bladder & 452 & 0 \\
\hline Bowl & 1097 & 0 \\
\hline Genitials & 204 & 0 \\
\hline Kidney & 2839 & 0 \\
\hline Liver & 6908 & 810 \\
\hline Major Vessels & 668 & 0 \\
\hline Mesentery & 107 & 0 \\
\hline Pancreas & 348 & 0 \\
\hline Spleen & 13302 & 6536 \\
\hline Stomach & 21 & 0 \\
\hline Other & 84 & 0 \\
\hline Side Oblique Far Side & Driver & Passenger \\
\hline Bladder & 0 & 0 \\
\hline Bowl & 0 & 0 \\
\hline Genitials & 0 & 0 \\
\hline Kidney & 183 & 324 \\
\hline
\end{tabular}


Table C1 (continued)

\begin{tabular}{|c|c|c|}
\hline \multicolumn{3}{|l|}{ ABDOMEN } \\
\hline Liver & 696 & 41 \\
\hline Major Vessels & 0 & 0 \\
\hline Mesentery & 0 & 0 \\
\hline Pancreas & 0 & 0 \\
\hline Spleen & 802 & 1853 \\
\hline Stomach & 0 & 0 \\
\hline Side Oblique Near Side & Driver & Passenger \\
\hline Bladder & 283 & 0 \\
\hline Bowl & 152 & 0 \\
\hline Genitials & 40 & 0 \\
\hline Kidney & 552 & 717 \\
\hline Liver & 1543 & 389 \\
\hline Major Vessels & 155 & 15 \\
\hline Mesentery & 13 & 242 \\
\hline Pancreas & 37 & 0 \\
\hline Spleen & 9125 & 1006 \\
\hline Stomach & 0 & 0 \\
\hline Not classified & 10 & 0 \\
\hline \multicolumn{3}{|l|}{ SPINE } \\
\hline Frontal Impact & Driver & Passenger \\
\hline Brachial Flexus & 78 & 0 \\
\hline Cervical Spinal Cord & 658 & 49 \\
\hline Thoracic Spinal Cord & 239 & 9 \\
\hline Cervical Disc Injury & 407 & 0 \\
\hline Cervical Dislocation & 1038 & 819 \\
\hline Cervical Vertebral Fracture & 58861 & 8935 \\
\hline Thoracic vertebral Fracture & 20143 & 5650 \\
\hline Lumbar Disc Injury & 1034 & 0 \\
\hline Lumbar Vertebral Fracture & 123710 & 18440 \\
\hline Frontal Oblique Far Side & Driver & Passenger \\
\hline Thoracic vertebral Fracture & 954 & 403 \\
\hline Lumbar Vertebral Fracture & 479 & 2360 \\
\hline Lumbar Dislocation & 435 & 0 \\
\hline Cervical Vertebral Fracture & 293 & 67 \\
\hline Cervical Dislocation & 216 & 0 \\
\hline Frontal Oblique Near Side & Driver & Passenger \\
\hline Cervical Disc Injury & 2582 & 0 \\
\hline Cervical Dislocation & 84 & 0 \\
\hline Thoracic Vertebral Fracture & 1580 & 49 \\
\hline Lumbar Vertebral Fracture & 24461 & 718 \\
\hline Thoracic Spinal Cord & 0 & 108 \\
\hline Cervical Vertebral Fracture & 19874 & 643 \\
\hline Side Impact Far Side & Driver & Passenger \\
\hline Thoracic Spinal Cord & 43 & 0 \\
\hline Cervical Vertebral Fracture & 5661 & 0 \\
\hline Lumbar Vertebral Fracture & 5455 & 1493 \\
\hline Side Impact Near Side & Driver & Passenger \\
\hline Thoracic Spinal Cord & 77 & 0 \\
\hline Cervical Disc Injury & 438 & 0 \\
\hline Thoracic Vertebral Fracture & 1628 & 99 \\
\hline Lumbar Vertebral Fracture & 13689 & 0 \\
\hline Cervical Spinal Cord & 0 & 8 \\
\hline Cervical Vertebral Fracture & 3071 & 669 \\
\hline Side Oblique Far Side & Driver & Passenger \\
\hline Cervical Dislocation & 88 & 0 \\
\hline Thoracic Vertebral Fracture & 415 & 184 \\
\hline Lumbar Vertebral Fracture & 15146 & 1817 \\
\hline Cervical Vertebral Fracture & 0 & 312 \\
\hline Side Oblique Near Side & Driver & Passenger \\
\hline Thoracic Spinal Cord & 21 & 97 \\
\hline Cervical Dislocation & 171 & 0 \\
\hline Thoracic Vertebral Fracture & 755 & 0 \\
\hline Lumbar Dislocation & 21 & 0 \\
\hline Lumbar Vertebral Fracture & 31383 & 0 \\
\hline Cervical Spinal Cord & 0 & 8 \\
\hline Cervical Vertebral Fracture & 2316 & 73 \\
\hline Not Available & 10 & 0 \\
\hline \multicolumn{3}{|l|}{ UPPER EXTRIMITIES } \\
\hline Frontal Impact & Driver & Passenger \\
\hline Arm Fracture Forearm & 1088 & 0 \\
\hline Arm Fracture NFS & 32236 & 8199 \\
\hline
\end{tabular}


Table C1 (continued)

\begin{tabular}{|c|c|c|}
\hline UPPER EXTRIMITIES & & \\
\hline Elbow Joint & 38 & 0 \\
\hline Forearm Fracture & 251931 & 38177 \\
\hline Hand & 673 & 0 \\
\hline Humerus Fracture & 13277 & 1792 \\
\hline Other & 1191 & 170 \\
\hline Shoulder & 78552 & 20173 \\
\hline Wrist Joint & 195791 & 13367 \\
\hline Not Available & 111 & 0 \\
\hline Frontal Oblique Far Side & Driver & Passenger \\
\hline Arm Fracture Forearm & 13 & 0 \\
\hline Arm Fracture NFS & 1964 & 0 \\
\hline Elbow Joint & 0 & 0 \\
\hline Forearm Fracture & 20331 & 6677 \\
\hline Hand & 203 & 0 \\
\hline Humerus Fracture & 997 & 1757 \\
\hline Other & 0 & 0 \\
\hline Shoulder & 18898 & 1751 \\
\hline Wrist Joint & 9081 & 307 \\
\hline Frontal Oblique Near Side & Driver & Passenger \\
\hline Arm Fracture Forearm & 1666 & 0 \\
\hline Arm Fracture NFS & 1861 & 1412 \\
\hline Elbow Joint & 0 & 0 \\
\hline Forearm Fracture & 30251 & 2357 \\
\hline Hand & 0 & 0 \\
\hline Humerus Fracture & 4673 & 703 \\
\hline Other & 445 & 0 \\
\hline Shoulder & 17273 & 6748 \\
\hline Wrist Joint & 22479 & 2893 \\
\hline Not Available & 77 & 0 \\
\hline Side Impact Far Side & Driver & Passenger \\
\hline Arm Fracture Forearm & 167 & 0 \\
\hline Arm Fracture NFS & 72 & 0 \\
\hline Elbow Joint & 0 & 0 \\
\hline Forearm Fracture & 0 & 0 \\
\hline Hand & 0 & 0 \\
\hline Humerus Fracture & 1212 & 318 \\
\hline Other & 0 & 0 \\
\hline Shoulder & 2138 & 780 \\
\hline Wrist Joint & 0 & 0 \\
\hline Side Impact Near Side & Driver & Passenger \\
\hline Arm Fracture Forearm & 0 & 0 \\
\hline Arm Fracture NFS & 0 & 0 \\
\hline Elbow Joint & 0 & 0 \\
\hline Forearm Fracture & 2730 & 0 \\
\hline Hand & 0 & 0 \\
\hline Humerus Fracture & 1340 & 0 \\
\hline Other & 21 & 0 \\
\hline Shoulder & 13342 & 0 \\
\hline Wrist Joint & 1993 & 0 \\
\hline Side Oblique Far Side & Driver & Passenger \\
\hline Arm Fracture Forearm & 0 & 0 \\
\hline Arm Fracture NFS & 0 & 0 \\
\hline Elbow Joint & 0 & 0 \\
\hline Forearm Fracture & 1651 & 2264 \\
\hline Hand & 0 & 0 \\
\hline Humerus Fracture & 161 & 0 \\
\hline Other & 0 & 0 \\
\hline Shoulder & 1855 & 1347 \\
\hline Wrist Joint & 3215 & 428 \\
\hline Side Oblique Near Side & Driver & Passenger \\
\hline Arm Fracture Forearm & 0 & 0 \\
\hline Arm Fracture NFS & 0 & 75 \\
\hline Elbow Joint & 0 & 0 \\
\hline Forearm Fracture & 2799 & 0 \\
\hline Hand & 0 & 0 \\
\hline Humerus Fracture & 750 & 0 \\
\hline Other & 0 & 0 \\
\hline Shoulder & 33170 & 4312 \\
\hline Wrist Joint & 8490 & 0 \\
\hline \multicolumn{3}{|l|}{ LOWER EXTRIMITIES } \\
\hline Frontal Impact & Driver & Passenger \\
\hline Ankle Joint & 150288 & 29341 \\
\hline Femur NFS & 7540 & 544 \\
\hline
\end{tabular}


Table C1 (continued)

\begin{tabular}{|c|c|c|}
\hline \multicolumn{3}{|l|}{ LOWER EXTRIMITIES } \\
\hline Femur Shaft & 33553 & 4365 \\
\hline Foot & 114310 & 4999 \\
\hline Hip Joint & 12378 & 1874 \\
\hline Knee Joint & 146318 & 22019 \\
\hline Lower Leg NFS & 108101 & 16422 \\
\hline Lower Leg Shaft & 24867 & 4352 \\
\hline Not Available & 582 & 259 \\
\hline Other & 12210 & 602 \\
\hline Pelvis & 64397 & 8904 \\
\hline Frontal Oblique Far Side & Driver & Passenger \\
\hline Ankle Joint & 5358 & 1743 \\
\hline Femur NFS & 0 & 0 \\
\hline Femur Shaft & 423 & 0 \\
\hline Foot & 581 & 140 \\
\hline Hip Joint & 1614 & 44 \\
\hline Knee Joint & 11258 & 177 \\
\hline Lower Leg NFS & 276 & 0 \\
\hline Lower Leg Shaft & 114 & 175 \\
\hline Not Available & 0 & 0 \\
\hline Other & 468 & 0 \\
\hline Pelvis & 4413 & 113 \\
\hline Frontal Oblique Near Side & Driver & Passenger \\
\hline Ankle Joint & 18703 & 3358 \\
\hline Femur NFS & 1914 & 0 \\
\hline Femur Shaft & 6354 & 655 \\
\hline Foot & 10712 & 1655 \\
\hline Hip Joint & 5444 & 606 \\
\hline Knee Joint & 12341 & 2416 \\
\hline Lower Leg NFS & 14090 & 3744 \\
\hline Lower Leg Shaft & 4566 & 641 \\
\hline Not Available & 0 & 0 \\
\hline Other & 8380 & 51 \\
\hline Pelvis & 53059 & 10383 \\
\hline Side Impact Far Side & Driver & Passenger \\
\hline Ankle Joint & 0 & 0 \\
\hline Femur NFS & 0 & 0 \\
\hline Femur Shaft & 0 & 0 \\
\hline Foot & 0 & 0 \\
\hline Hip Joint & 108 & 140 \\
\hline Knee Joint & 992 & 0 \\
\hline Lower Leg NFS & 0 & 0 \\
\hline Lower Leg Shaft & 0 & 0 \\
\hline Not Available & 0 & 0 \\
\hline Other & 0 & 0 \\
\hline Pelvis & 7186 & 9312 \\
\hline Side Impact Near Side & Driver & Passenger \\
\hline Ankle Joint & 1535 & 139 \\
\hline Femur NFS & 957 & 0 \\
\hline Femur Shaft & 823 & 421 \\
\hline Foot & 0 & 0 \\
\hline Hip Joint & 338 & 0 \\
\hline Knee Joint & 1349 & 0 \\
\hline Lower Leg NFS & 4154 & 0 \\
\hline Lower Leg Shaft & 1083 & 0 \\
\hline Not Available & 0 & 0 \\
\hline Other & 0 & 0 \\
\hline Pelvis & 74962 & 15076 \\
\hline Side Oblique Far Side & Driver & Passenger \\
\hline Ankle Joint & 9182 & 551 \\
\hline Femur NFS & 131 & 0 \\
\hline Femur Shaft & 3215 & 589 \\
\hline Foot & 1137 & 0 \\
\hline Hip Joint & 2858 & 0 \\
\hline Knee Joint & 12350 & 1961 \\
\hline Lower Leg NFS & 5713 & 551 \\
\hline Lower Leg Shaft & 3693 & 0 \\
\hline Not Available & 0 & 0 \\
\hline Other & 1831 & 0 \\
\hline Pelvis & 1290 & 1201 \\
\hline Side Oblique Near Side & Driver & Passenger \\
\hline Ankle Joint & 2399 & 2175 \\
\hline Femur NFS & 60 & 0 \\
\hline Femur Shaft & 2558 & 0 \\
\hline Foot & 0 & 0 \\
\hline Hip Joint & 563 & 0 \\
\hline
\end{tabular}


Table C1 (continued)

\begin{tabular}{lll}
\hline LOWER EXTRIMITIES & & \\
\hline Knee Joint & 6263 & 3 \\
Lower Leg NFS & 11056 & 0 \\
Lower Leg Shaft & 296 & 0 \\
Not Available & 10 & 0 \\
Other & 776 & 100 \\
Pelvis & 86191 & 5914 \\
\hline
\end{tabular}

\section{References}

Elemance, 2018. Virtual Human Body Models. Internet http://www.elemance.com/ virtual-human-body-models/. [cited 2018 Nov 26th]. .

Foster, J.K., Kortege, J.O., Wolanin, M.J., 1977. Hybrid III - a biomechanically-based test dummy. Stapp Car Crash J. Vol, 31 (October 1977) SAE 770938.

Guleyupoglu, B., Koya, B., Barnard, R., Gayzik, F.S., 2018. Failed rib region prediction in a human body model during crash events with precrash braking. Traffic Inj. Prev. 19 (February (sup1)), S37-S43. https://doi.org/10.1080/15389588.2017.1395873.

Iraeus, J., Lindquist, M., 2015. Development and Validation of a Generic Finite Element Vehicle Buck Model for the Analysis of Driver Rib Fractures in Real Life Nearside Frontal Crashes. Accident Analysis and Prevention.

Kleiven, S., 2007. Predictors for Traumatic Brain Injuries Evaluated through Accident Reconstructions. Stapp Car Crash J. 51 (October 2007), 81-114.

Klinich, K.D., Flannagan, C.A., Hu, J., Reed, M.P., 2016. Potential safety effects of low-mass vehicles with comprehensive crash avoidance technology. Paper Presented at: IRCOBI Conference Proceedings.

Kononen, D.W., Flannagan, C.A.C., Wang, S.C., 2011. Identification and validation of a logistic regression model for predicting serious injuries associated with motor vehicle crashes. Accid. Anal. Prev. 43 (1), 112-122. https://doi.org/10.1016/j.aap.2010.07. 018.

Lowne, R., Neilson, J., 1987. The development and certification of EUROSID. In: Eleventh International Technical Conference on Experimental Safety Vehicles. NHTSA. pp. 1987.

Mao, H., Zhang, L., Jiang, B., Genthikatti, V.V., Jin, X., Zhu, F., Makwana, R., Gill, A., Jandir, G., Singh, A., Yang, K.H., 2013. Development of a finite element human head model partially validated with thirty five experimental cases. J. Biomech. Eng. 135 (November (11)), 111002. https://doi.org/10.1115/1.4025101.

Neilson, L., Lowne, R., Tarriere, C., Bendjellal, F., Gillet, D., Maltja, J., Cesari, D., Bouquet, R., 1985. The EUROSID side impact dummy. In: Tenth International
Technical Conference on Experimental Safety Vehicles. NHTSA. pp. 1985.

Östling, M., Puthan, P., Jeppsson, H., Lubbe, N., Sunnevång, C., 2018. Future passive safety needs: predicted injury patterns and possible countermeasures. In: Airbag 2018 Conference, November 26-28. Mannheim. Germany.

Page, M., 2001. Performance of the prototype WorldSID dummy in Side impact crash tests. $17^{\text {Th }}$ Enhanced Safety of Vehicle Conference, Paper No. 482.

Parent, D., Craig, M., Ridella, S., McFadden, J., 2013. Thoracic Biofidelity Assessment of the THOR Mod Kit ATD," 23rd Enhanced Safety of Vehicles Conference, Paper No. 13-0327. pp. 2013.

Rouhana, S.W., Bedewi, P.G., Prasad, P., 2003. Biomechanics of 4-point seat belt systems in frontal impact. Fourty -Sventh Stapp Car Crash Conference.

SAE J224, 1980. Collision Deformation Classification SAE J224 Mar80. Society of Automotive Engineers, Warrendale, PA.

Sahoo, D., Deck, C., Willinger, R., 2014. Development and validation of an advanced anisotropic visco-hyperelastic human brain FE model. J. Mech. Behav. Biomed. Mater. 33, 24-42.

Toyota Central R\&D Labs. INC, 2018. Human Body Models for Injury Analysis THUMS ${ }^{\circledast}$. Internet https://www.tytlabs.com/tech/thums/index.html. [cited 2018 Nov 26th]. .

van Ratingen, M., Williams, A., Lie, A., et al., 2016. The European New Car Assessment Programme: a historical review. Chin. J. Traumatol. 19 (2), 63-69. https://doi.org/ 10.1016/j.cjtee.2015.11.016.

Weaver, A., Ryan, B., Kilgo, P., Martin, S., Stitzel, J., 2013. Mortality-based quantification of injury severity for frequently occurring motor vehicle crash injuries. $57^{\text {Th }}$ AAAM Annual Conference Annal of Advances in Automotive Medicine, September 22-25 2013.

Weaver, A., Talton, W., Barnard, R., Schoell, S., Swett, K., Stotzel, J., 2015. Estimated injury risk for specific injuries and body regions in frontal motor vehicle crashes. Traffic Inj. Prev. 16 (suppl. 1), S108-S116. https://doi.org/10.1080/15389588.2015. 10.1012664 